\title{
Woman with Unclassified Mullerian Anomaly, Polycystic Ovary Syndrome and Infertility: A Case Report
}

Dr. Shakeela Ishrat" ${ }^{1 *}$, Dr Farhana Parveen ${ }^{2}$, Dr. Muhammad Jasim Uddin ${ }^{3}$, Dr. Sabiha Sultana ${ }^{4}$, Dr. Mehnaz Mushtary Shume $^{5}$, Dr. Serazoom Munira ${ }^{6}$, Dr. Sheikh Farhana $\mathrm{Huda}^{7}$

${ }^{1}$ Dr. Shakeela Ishrat, Associate Professor, Department of Reproductive Endocrinology and Infertility, Bangabandhu Sheikh Mujib Medical University, Dhaka, Bangladesh

${ }^{2}$ Dr Farhana Parveen, Consultant, Department of Reproductive Endocrinology and Infertility, Bangabandhu Sheikh Mujib Medical University, Dhaka, Bangladesh

${ }^{3}$ Dr Muhammad Jasim Uddin, Consultant, Department of Reproductive Endocrinology and Infertility, Bangabandhu Sheikh Mujib Medical University, Dhaka, Bangladesh

${ }^{4}$ Dr. Sabiha Sultana, Consultant, Department of Reproductive Endocrinology and Infertility, Bangabandhu Sheikh Mujib Medical University, Dhaka, Bangladesh

${ }^{5}$ Dr. Mehnaz Mushtary Shume, Consultant, Department of Reproductive Endocrinology and Infertility, Bangabandhu Sheikh Mujib Medical University, Dhaka, Bangladesh

${ }^{6}$ Dr. Serazoom Munira, Consultant, Department of Reproductive Endocrinology and Infertility, Bangabandhu Sheikh Mujib Medical University, Dhaka, Bangladesh

${ }^{7}$ Dr. Sheikh Farhana Huda, Consultant, Department of Gynae Oncology, Bangabandhu Sheikh Mujib Medical University, Dhaka, Bangladesh

DOI: $10.36348 /$ sijog.2021.v04i03.006

| Received: 19.02.2021 | Accepted: 25.03.2021 | Published: 30.03.2021

*Corresponding author: Dr. Shakeela Ishrat

\section{Abstract}

Mullerian anomalies cannot always be defined in one or the other class, as described by the American Society of Reproductive Medicine. One such unclassified anomaly incidentally found in a infertile women with polycystic ovary syndrome, was difficult to diagnose with existing imaging modalities. The final diagnosis was not made until after the surgeries including diagnostic laparoscopy and hysteroscopy.

Keywords: Mullerian duct anomalies, polycystic ovary syndrome, infertility.

Copyright $(92021$ The Author(s): This is an open-access article distributed under the terms of the Creative Commons Attribution 4.0 International License (CC BY-NC 4.0) which permits unrestricted use, distribution, and reproduction in any medium for non-commercial use provided the original author and source are credited.

\section{INTRODUCTION}

Genitourinary tract anomalies are extremely commom in females (5.5\% of the general population), more common in infertile women (8\%) and in women with miscarriage or other adverse obstetric outcomes (25\%) [1]. The classification of uterine anomalies by American Society of Reproductive Medicine is commonly followed by the gynecologists and reproductive endocrinologists. The classification includes hypoplastic uterus, unicornuate uterus, didelphys uterus, bicornuate uterus, septate uterus, arcuate uterus and the t-shaped uterus after DES exposure in utero [2]. There are some anomalies that are not included in the seven classes in this classification [3].
According to the theory of Mullerian development, a double cervix is associated only with uterus didelphys [4].Uterus didelphys results from complete failure of fusion of the Mullerian ducts, leading to two uterus and two cervices. A longitudinal vaginal septum, either thick or thin is also present [5]. A complete septate uterus has a single uterine fundus. A septum extends from the top of the endometrial cavity and continues to a single or duplicated cervix. Both may be associated with a longitudinal septum [6]. We had a case that was neither uterus didelphys nor complete septate uterus but a hybrid septate variant [7].

A retrospective evaluation of 3033 infertile women in Turkey revealed that $8 \%$ of PCOS (polycystic ovarian syndrome) women had uterine 
anomalies in contrast to $3 \%$ in non PCOS women. There was significant association of PCOS with uterine anomalies in infertile women [8]. The coexistence of Mullerian anomalies with PCOS makes the management of infertile woman more difficult.

\section{CASE PRESENTATION}

A 20 year old nulliparous woman presents at the outpatient department of Reproductive Endocrinology and Infertility with the complaints of failure to conceive for last 3 years of conjugal life and infrequent menstruation for last one year.

The woman states that she is married for last 3 years and has been living with her husband with adequate coital frequency and no coital difficulty. She had menarche at 12 years of age and since then has regular menstrual cycle at an interval of $28 \pm 2$ days, menstrual period lasting for 7-8 days with average flow. But for last one year her menstruation has been infrequent at 2-3 months interval, lasting for 10-12 days, with decreased amount of menstrual flow. However there is no associated dysmenorrhoea.

On examination she appears to be of average body weight, with no apparent hirsutism or acanthosis nigricans. On vaginal examination, there was a longitudinal vaginal septum, two cervical openings, the right one easily visible. On transvaginal sonogram, the ovaries appear enlarged and polycystic. There are two separate endometrial cavities (Figure 1).

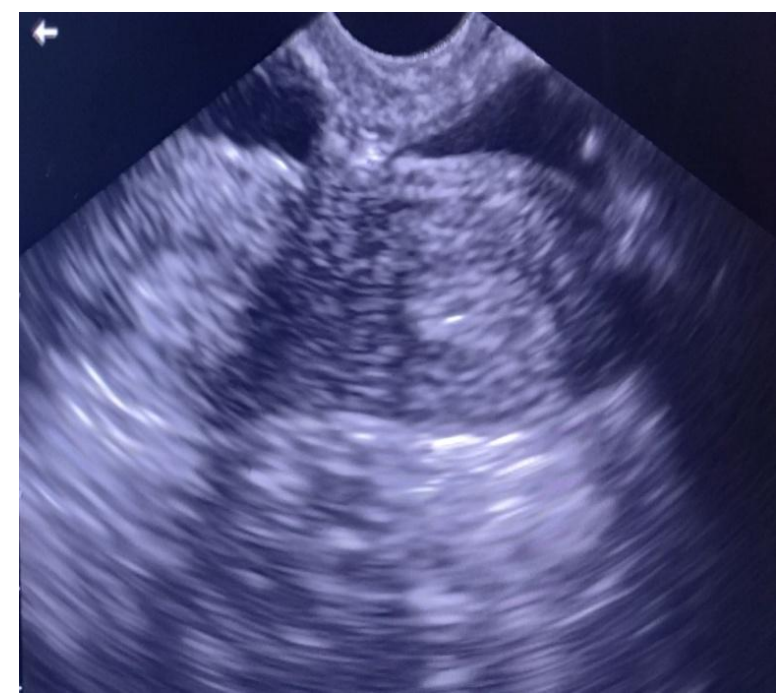

Fig-1: Transvaginal sonogram showing two separate endometrial cavities, suggestive of either bicornuate uterus or septate uterus.

During infertility work up, semen analysis of husband reveals normoozospermia. Infrequent menstruation, sonographic appearance of large polycystic ovaries, high LH: FSH ratio and high AMH, all are in favour of diagnosis of chronic anovulation due to polycystic ovary syndrome. As the woman is young with only three years of infertility we suggested hysterosalpingogram for the evaluation of uterine cavity and tubal patency. The hysterosalpingogram report was unicornuate uterus with tubal block (Figure 2). The instillation of dye was done only through the more apparent cervical opening.

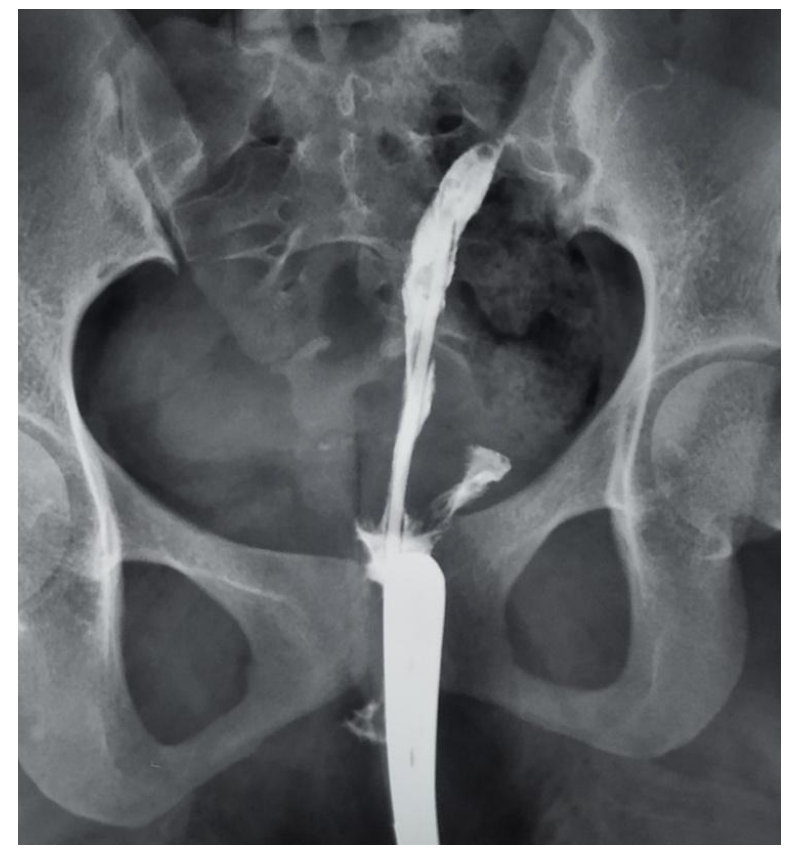

Fig-2: Hysterosalpingography with possible instillation of dye through the more apparent cervix

Investigation profile of the couple is summarized in Table 1.

Table-I: Laboratory findings

\begin{tabular}{|l|l|l|}
\hline \multicolumn{3}{|c|}{ Laboratory findings } \\
\hline Parameter & Patient & $\begin{array}{l}\text { Reference } \\
\text { value }\end{array}$ \\
\hline $\begin{array}{l}\text { D2 Follicle stimulating } \\
\text { hormone }\end{array}$ & $3 \mathrm{IU} / \mathrm{L}$ & $\begin{array}{l}2.8-11.3 \\
\mathrm{IU} / \mathrm{L}\end{array}$ \\
\hline D2 Lutinizing hormone & $\begin{array}{l}16.18 \\
\mathrm{mIU} / \mathrm{ml}\end{array}$ & $\begin{array}{l}1.1-11.6 \\
\mathrm{mIU} / \mathrm{ml}\end{array}$ \\
\hline Anti Mullerian hormone & $13.59 \mathrm{ng} / \mathrm{ml}$ & $4-6.8 \mathrm{ng} / \mathrm{ml}$ \\
\hline Prolactin & $15.5 \mathrm{ng} / \mathrm{ml}$ & $1.9-25 \mathrm{ng} / \mathrm{ml}$ \\
\hline $\begin{array}{l}\text { Thyroid stimulation } \\
\text { hormone }\end{array}$ & $3.4 \mu \mathrm{IU} / \mathrm{ml}$ & $\begin{array}{l}0.35-5.50 \\
\mu \mathrm{IU} / \mathrm{ml}\end{array}$ \\
\hline
\end{tabular}

The provisional diagnosis is PCOS and uterus didelphys (double uterus with two separate cervices) with longitudinal vaginal septum. The differential diagnosis was PCOS and complete septate uterus with septate cervix and vagina.

Surgery following examination under
anesthesia was planned. Since the
hysterosalphingography had abnormal findings, we
decided for her diagnostic laparoscopy and
hysteroscopy. After incision of the longitudinal
vaginal septum two different cervical openings were
identified; one cervix appeared to be more developed
than the other (Figure 3). Diagnostic laparoscopy was

(C) 2021 Published by Scholars Middle East Publishers, Dubai, United Arab Emirates 
Shakeela Ishrat et al; Sch Int J Obstet Gynec, Mar. 2021; 4(3): 72-75

done. Uterus was bicornuate, with fundal indentation (Figure 4). Both ovaries were enlarged with smooth and pearly white surface, as usual in polycystic ovary syndrome. On chromo-pertubation, there was free spillage on both sides confirming bilateral tubal patency.

Laparoscopic ovarian drilling was done. Hysteroscopy revealed that there were two separate cavities, only one osteum visible in each cavity. So the diagnosis was complete uterine septum, extending into duplicated cervix. The final diagnosis was PCOS and bicornuate uetrus with septate cervix and vagina.

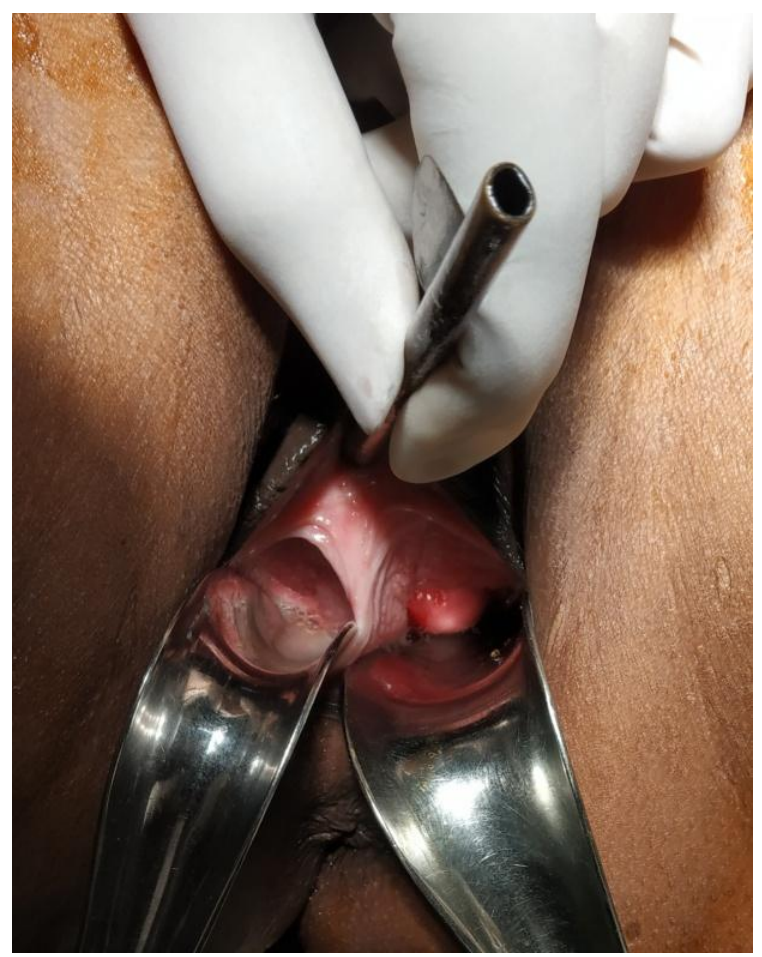

Fig-3: Longitudinal vaginal septum with cervix visible on left side

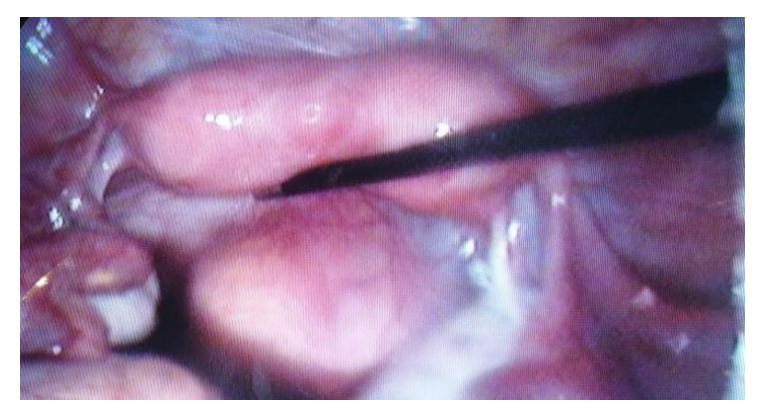

Fig-4: Bicornuate uterus, indentation not complete as in uterus didelphys

Our patient is only 20 year old, with 3 years infertility and an obvious ovarian factor like polycystic ovary syndrome. Since the tubes are patent, we will go for ovulation induction for her if there is no pregnancy for 6 months following laparoscopic ovarian drilling. We will counsel her about the risk of miscarriage and other adverse outcomes in case she gets pregnant and the need for close follow up.

\section{DISCUSSION}

Traditionally the embryological development of female genital tract is thought to involve three processes: lateral fusion, vertical fusion and resorption. The lateral fusion of the two Mullerian ducts may be unidirectional in caudal to cranial direction or bidirectional from the region of isthmus [9]. Anomalies [5] may result from

I. Complete or partial failure of Mullerian duct development (Mullerian agenesis, unicornuate uterus without a rudimentary horn)

II. Failure of Mullerian ducts to canalize (unicornuate uterus with a rudimentary horn without proper cavities)

III. Incomplete fusion of Mullerian ducts (bicornuate or didelphys uterus)

IV. Incomplete reabsorption of uterine septum after fusion is complete (septate or arcuate uterus)

The Mullerian anomalies are usually classified on the basis of uterine configuration. The classification was proposed by American Fertility Society in 1988. It has been accepted widely over the last 25 years. The classification is grossly as follows : class I hypoplasia/agenesis, class II uterus unicornuate, class III uterus didelphys, class IV uterus bicornuate, class V septate uterus, class VI arcuate uterus, class VII T shaped uterus [10]. A more comprehensive system of classification has been developed by the European Society of Human Reproduction and Embryology where cervical and vaginal anomalies are included in independent subclasses [9, 10]. Septate uterus is the most common Mullerian duct anomaly (55\%).

The final diagnosis made by the gold standard method of laparoscopy and hysteroscopy was bicornuate uterus with septate cervix and vagina. The anomaly is rare and reflects segmentary defects and a discrepancy in the fusion and resorption process. The condition is a fusion defect of upper uterine segment (diverging portion of the Mullerian duct) and a resorption defect of the inferior segment and vagina (converging portion of the Mullerian duct) $[6,11]$. The anomaly has also been described as hybrid septate variant [7]. External fundal depression of variable length gives the impression of bicornuate uterus at laparoscopy, but there is concomitant complete uterine, cervical and vaginal septum.

Imaging techniques like 2 -dimensional ultrasonography and hysterosalpingography are helpful for diagnosis of uterus didelphys, bicornuate uterus and septate uterus. Accuracy of coronal view 4-D ultrasound and MRI is more, reportedly $96-100 \%$ for diagnosis of uterine and cervical anomalies [10]. Accurate diagnosis, if possible, by imaging techniques 
Shakeela Ishrat et al; Sch Int J Obstet Gynec, Mar. 2021; 4(3): 72-75

will ensure appropriate counseling and adequate preoperative planning.

Some authors believe that union of the cervices increases the risk of cervical incompetence and resection of uterine septum without division of cervical septum is challenging. Others prefer resection of cervical septum to make hysteroscopic metroplasty easier, faster and safer [12]. Many women with a septate uterus can be pregnant with positive outcome and there is no evidence based cause-effect relationship between septate uterus and infertility. Prophylactic metroplasty to prevent miscarriage or other adverse obstetric outcomes is planned in women with prolonged infertility, in women older than 35 years and in women decided for assisted reproductive techniques [13].

There is association of PCOS with mullerian anomalies in infertile women. The possible explanations include high levels of AMH in PCOS women and the role of $\mathrm{AMH}$ in degeneration of mullerian ducts in early embryonic life. The other explanation may be a common developmental defect leading to both PCOS and uterine anomalies [8].

\section{CONCLUSION}

The reported case of bicornuate uterus with septate cervix and vagina adds to the uncommon and unclassified Mullerian anomalies in women. Mullerian anomalies can coexist with polycystic ovary syndrome in infertile women, meaning additional challenge to fertility management.

\section{REFERENCES}

1. Antunes, I. L., Tomas, C., Bravo, I., Mettelo, J. L., Quintus, A., Sa e Melo, P. (2019. Double cervix with Normal Uterus and Vagina-an Unclassified Mullerian anomaly. Int J Fertil Steril, 13(1),83-5

2. Badawy, S.Z.A., Makin, J. (2015). Uterine anomalies, unclassified. Middle East Fertility Society Journal, 21,1-3

3. Jagannathan, D., Indiran, V. (2018). Magnetic resonance imaging of classified and unclassified Mullerian duct anomalies: Comparison of the American Society of Reproductive Medicine and the European Society of Human Reproduction and
Embryology Classifications. S Afr Rad, 22(1),a1259

4. Smith, B.C., Brown, D.L., Carter, R.E., Famuyide, A.O. (2014). Double cervix: Clarifying a diagnostic dilemma. Am J Obstet Gynecol, 211,26,e1-5

5. Rezai, S., Bisram, P., Alcantara, I., Upadhyay, R., Lara, C., Elmadjian, M. (2015). Didephys uterus: a Case Report and Review of the Literature. Case reports in Obstetrics \& Gynaecology, 5.

6. Practice committee of the American society of Reproductive Medicine. (2016).Uterine septum: a guideline. Fertil Steril,106(3):530-40

7. El Saman, A.M., Shahin, A.Y., Nasr, A., Tawfik, R.M., Saadeldeen, H.S., Othman, E.R. (2012). Hybrid septate uterus, coexistense of bicornuate and septate varieties: A genuine report. $J$ Obs Gynae Res, 38(11), 1304-14

8. Ege, S., Peker, N., Bademkiran, M.H. (2019). The prevalence of uterine anomalies in infertile patients with polycystic ovary syndrome: A retrospective study in a tertiary centre in Southeastern Turkey. Turk Obstet Gynecol, 16,224-7

9. Celik, N.Y., Mulayim, B. A. (2012). Mulllerian anomaly "without classification": Septate uterus with double cervix and longitudinal vaginal septum. Taiwanese Journal of Obstetrics \& Gynaecology, 51,649-50

10. Ludwin, A., Ludwin, I. (2015). Comparison of the ESHRE-ESGE and ASRM classification of Mullerian duct anomalies in everyday practice. Hum Reprod, 30(3),569-80

11. Acien, P., Acien, M., Sanchez Ferrar, M.L. (2009). Mullerian anomalies "without a classification": from the didelphys-unicollis uterus to the bicervical uterus with or without septate vagina. Fertil Steril, 96(6), 2369-75

12. Ribeiro, S.C., Yamakami, L.Y.S.,Tormena, R.A., Pinheiro, W.D.S., Almeida, J.A.M., Barakat, E.C. (2010) Septate uterus with cervical duplication and longitudinal vaginal septum. Rev Assoc Med Bras, 56(2):254-6

13. Rackow, B.W., Arici, A. (2007). Reproductive performance of women with mullerian anomalies. Curr Opin Obstet Gynecol, 19,229-37. 